\title{
THE IMPACT OF AGGREGATE MORTALITY RISK ON DEFINED BENEFIT PENSION PLANS
}

\author{
Irena Dushi, Leora Friedberg, and Anthony Webb*
}

CRR WP 2006-21

Released: November 2006

Draft Submitted: October 2006

\author{
Center for Retirement Research at Boston College \\ 258 Hammond Street \\ Chestnut Hill, MA 02467 \\ Tel: 617-552-1762 Fax: 617-552-0191 \\ http://www.bc.edu/crr
}

* Irena Dushi is an analyst at the U.S. Social Security Administration. Leora Friedberg is an economics professor at the University of Virginia. Anthony Webb is a research economist at the Center for Retirement Research at Boston College. The research reported herein was performed pursuant to a grant from the U.S. Social Security Administration (SSA) funded as part of the Retirement Research Consortium. The findings and conclusions expressed are solely those of the authors and do not represent the views of SSA, any agency of the Federal Government, the University of Virginia, or Boston College. Please send any inquiries to Anthony Webb at webbaa@bc.edu. The authors would like to thank Clark Burdick and Javier Meseguer at SSA for very helpful discussion, and Ed Burrows, Steve Sass, and Francis Vitagliano for their very helpful comments.

(C) 2006, by Irena Dushi, Leora Friedberg, and Anthony Webb. All rights reserved. Short sections of text, not to exceed two paragraphs, may be quoted without explicit permission provided that full credit, including (C) notice, is given to the source. 


\title{
About the Center for Retirement Research
}

The Center for Retirement Research at Boston College, part of a consortium that includes parallel centers at the University of Michigan and the National Bureau of Economic Research, was established in 1998 through a grant from the Social Security Administration. The goals of the Center are to promote research on retirement issues, to transmit new findings to the policy community and the public, to help train new scholars, and to broaden access to valuable data sources. Through these initiatives, the Center hopes to forge a strong link between the academic and policy communities around an issue of critical importance to the nation's future.

\author{
Center for Retirement Research at Boston College \\ 258 Hammond Street \\ Chestnut Hill, MA 02467 \\ phone: 617- 552- 1762 fax: 617- 552- 0191 \\ e-mail: crr@bc.edu \\ www.bc.edu/crr
}

\author{
Affiliated Institutions: \\ American Enterprise Institute \\ The Brookings Institution \\ Center for Strategic and International Studies \\ Massachusetts Institute of Technology \\ Syracuse University \\ Urban Institute
}




\begin{abstract}
We calculate the risk faced by defined benefit plan providers arising from uncertain aggregate mortality - the risk that the average participant will live longer than expected. First, comparing the widely cited Lee-Carter model to industry benchmarks, we show that plan providers appear to substantially underestimate the longevity of their employees. The resultant understatement of liabilities is $15.2 \%$, when weighted by the characteristics of typical male participants in defined benefit plans, and reaches as much as $25.2 \%$ for male workers aged 22. Next, we consider the substantial mortality risk that arises even if plan providers were to use the Lee-Carter model or other unbiased forecasts of mortality reductions. We calculate the consequences for plan liabilities if aggregate mortality declines unexpectedly faster than is predicted by an unbiased projection. There is a $5 \%$ chance that liabilities of a terminated plan would be 2.9 to $5.1 \%$ higher than what is expected, depending on the mix of workers covered. Lastly, we explain how longevity bonds might be used to transfer mortality risk from defined benefit plans to the capital markets, and we calculate a risk premium for a hypothetical frozen plan.
\end{abstract}




\section{Introduction}

Annuities provide a means by which risk-averse households facing an uncertain lifespan can insure themselves against the risk of outliving their wealth. Yet, only $7.4 \%$ of a large sample of elderly households had voluntarily purchased an annuity between 1993 and 2000 (Dushi and Webb 2006). These purchases represent only a small proportion of household wealth held in annuitized form, though, because much household wealth is automatically annuitized through Social Security and defined benefit (DB) pensions offered by employers. The average married couple turning 65 between 1994 and 2000 had \$248,778 in Social Security wealth and \$154,810 in defined benefit pension wealth (Dushi and Webb 2004).

Annuity providers - be they insurance companies, private and public sector employers offering DB pension plans, or taxpayers through Social Security and the Pension Benefit Guaranty Corporation - face two kinds of mortality risk: idiosyncratic risk, since any particular annuitant may live longer than expected, and aggregate mortality risk, since annuitants may on average live longer than expected. ${ }^{1}$ Idiosyncratic risk can be eliminated by increasing the size of the annuitant pool, but aggregate mortality risk cannot.

Only a small part of this aggregate risk is held by the shareholders in insurance companies selling voluntary annuities. The vast majority is held by shareholders of companies providing DB plans to employees, by insurance companies providing deferred annuities to pension plans, and by taxpayers. ${ }^{2}$ In another paper, Friedberg and Webb (2006) focus on the consequences of aggregate mortality risk faced by voluntary annuity providers. To calculate the magnitude of this risk, they use the Lee-Carter (1992) mortality model, which - according to Deaton and Paxson (2004) - has become the

\footnotetext{
${ }^{1}$ Since adverse selection is not our focus, we ignore a third kind of risk, that the annuity provider may incorrectly estimate the degree of selection.

${ }^{2}$ Taxpayers meet the cost of public pensions. Private sector defined benefit pensions are insured by the Pension Benefit Guarantee Corporation (PBGC) through premiums paid by employers, which are likely to be passed through in turn to plan participants through lower wages or benefits. The PBGC only insures pensions up to certain limits, so higher paid employees also bear some aggregate mortality risk in the event of employer bankruptcy and plan underfunding; as do taxpayers in the event that the PBGC is underfunded.
} 
"leading statistical model of mortality in the demographic literature.”3 Friedberg-Webb conclude that an insurance company using the Lee-Carter model to price annuities would face a $5 \%$ chance that the present value of its payments would be $3-4 \%$ greater than expected, and a $1 \%$ chance that they would be $5-6 \%$ greater.

We extend the above research to consider the aggregate mortality risk faced by providers of DB pension plans. DB pension coverage has declined substantially in recent years in both the United States and the United Kingdom, and aggregate mortality risk is one of the factors that has explicitly been blamed in the United Kingdom. (ACA 2005, pp.13-14). ${ }^{4}$

We consider two aspects of aggregate mortality risk: the possibility that plan providers use mortality forecasts that are biased upward, compared to Lee-Carter or to the Social Security Administration forecasts, and the possibility that future mortality rates are lower than those predicted by these up-to-date, putatively unbiased forecasts. ${ }^{5}$ We first consider the likely magnitude and consequences of any bias in plan providers' mortality assumptions, a concern that has recently received the attention of regulators in the United Kingdom. ${ }^{6}$ Our inquiries and previous research both indicate that it is common practice for plan providers to base the estimates of pension liabilities that are reported in their financial statements on GAM83, a period mortality table reflecting 1983 mortality. ${ }^{7}$ Very recently, there has been a shift towards RP2000, a period table reflecting mortality in the year 2000. Though GAM83 incorporates a 10\% conservative margin, mortality rates have declined since both tables were compiled, and most forecasts project further declines. Our investigations further indicate that only a minority of plans adjust the period mortality table (e.g., GAM83 or RP2000) that they use to reflect subsequent

\footnotetext{
${ }^{3}$ The Lee-Carter model has been adopted by the U.S. Census Bureau, among others, and was viewed favorably by the Social Security Administration's 1999 technical advisory panel (The Social Security Technical Panel on Assumptions and Methods 1999, p.64).

${ }^{4}$ Among full-time employees with a pension in the Survey of Consumer Finances, $69 \%$ had a DB plan in 1983, while 39\% had a DB plan in 2001 (Friedberg and Owyang 2005).

${ }^{5}$ We focus on these consequences of aggregate mortality risk for obligations with respect to employee's service to date, which are straightforward to measure. We ignore the prospect that aggregate mortality risk will also influence the cost of providing benefits in relation to future service.

${ }^{6}$ The U.K. pension regulator issued a new warning on September 24, 2006 that companies are seriously understating their pension obligations because their assumptions of life expectancy are still too generous.

${ }^{7}$ This is a period table based on 1960s data, projected to 1983. A period mortality table shows mortality rates of people of various ages who are alive in a reference year. In contrast, a cohort table shows mortality rates of people born in a reference year.
} 
declines in mortality rates, and that any adjustments are typically made only to a current date and not over the expected lifetimes of plan participants.

We calculate the effect of this apparent forecasting bias on plan providers' pension liabilities. We find that, for older workers, the $10 \%$ conservative margin in GAM83 projected to a current date approximately offsets the effect of the mortality declines currently projected by the Social Security Administration over the remainder of the workers' lifetimes. For a plan that was experiencing typical group annuitant mortality in 1983, therefore, projecting GAM83 to a current date is expected to suffice for such workers. Moreover, liabilities would be substantially understated for plans with younger workers (unless those plans projected mortality improvements over the whole of their workers' lifetimes) and for any plan that does not project. For males, the understatement could amount to as much as $16.2 \%$, depending on the ages of the participants, if mortality rates decline at the rates predicted by the Social Security Administration in its intermediate assumptions. If mortality declines at the somewhat higher rates predicted by the Lee-Carter model, then the understatement could amount to as much as $25.2 \%$. For females, the understatements could amount to as much as $6.1 \%$ and $13.2 \%$, respectively.

We then consider the magnitude of risk inherent in an unbiased forecast of mortality improvements. We assume that the Lee-Carter model provides an unbiased forecast and, importantly, that the model captures the degree of uncertainty attached to that forecast. Our results are driven by the degree of uncertainty as reflected in the confidence intervals and not by the rate of decline. We run Monte-Carlo simulations of the evolution of aggregate mortality according to the Lee-Carter model and then calculate the impact of these mortality shocks on the projected benefit obligation of continuing plans, assuming a typical discount rate. ${ }^{8}$ We calculate that there is, in any year, a 5\% chance that an aggregate mortality shock could increase a provider's projected benefit obligation for male participants by $1.07 \%$, and a $1 \%$ chance that a shock could increase it by $1.41 \%$. The respective numbers for female participants are $0.82 \%$ and $1.07 \%$. We also compute the impact on the present value of obligations faced by providers of frozen plans. We calculate that for a hypothetical plan, there is a $5 \%(1 \%)$ probability that

\footnotetext{
${ }^{8}$ Defined benefit pension plans update their mortality assumptions at less frequent intervals, but our model is nonetheless a convenient way of quantifying and pricing the risk they face, and population level mortality data is indeed made available on an annual basis.
} 
reductions in aggregate mortality result in the present value of total future payments for male workers being at least 3.5\% (4.2\%) greater than expected. We then evaluate the aggregate mortality risk faced by S\&P 500 companies. Using data supplied by Credit Suisse First Boston, we conclude that, while the aggregate risk is not large relative to overall profits and stock market capitalization, it is quite substantial for a minority of companies.

The riskiness of the liability is sensitive to the interest rate used to discount the payments, being substantially greater at lower rates. One important implication is that inflation-protected pensions expose a provider to substantially greater aggregate mortality risk than nominal pensions, whose present value is calculated using a higher nominal rate of interest. Also, the percentage increase in liabilities from a given mortality shock is somewhat greater for pension providers than for insurance companies selling immediate annuities, as calculated in Friedberg and Webb (2006) using the same discount rate. In contrast to an immediate annuity, which, as its name suggests, comes into payment immediately, a pension is a deferred annuity, exposing the provider to only the high-risk long time-horizon obligations.

Our results suggest a role for capital markets to reallocate aggregate mortality risk to those most willing to bear it. Longevity bonds have been proposed as a mechanism to transfer aggregate mortality risk from annuity providers to the financial markets. ${ }^{9}$ The payments on such bonds would be based upon the survival rate of a reference population, for example American males aged 65 in 2006. Purchasing such bonds would insure an annuity provider against aggregate mortality risk to the extent that the provider's mortality experience mirrored that of the reference population.

Friedberg and Webb (2006) showed how such bonds can be priced using the Capital Asset Pricing Model (CAPM). The CAPM distinguishes between systematic risk and idiosyncratic risk, since the latter can be eliminated through diversification and does not command a risk premium. Applying the CAPM, the mortality risk premium will

\footnotetext{
${ }^{9}$ To date, only one such bond has been marketed, by the European Investment Bank. It was withdrawn prior to issue. As we discuss later, it is not clear whether the withdrawal reflected weaknesses in the bond's design or a lack of demand. Swiss Re has also recently issued mortality bonds. In contrast to longevity bonds that are long-term instruments designed to insure against mortality reductions, these are short-term instruments designed to insure against mortality increases. Mortality-contingent bonds have been the subject of two symposia; Pensions Institute (2005) summarizes discussions at the first, and Brown (2006) reviews issues surrounding such bonds.
} 
depend on the bond's beta - the correlation between market returns and the component of the bond's return related to aggregate mortality risk. ${ }^{10}$ Friedberg-Webb show that the historical correlation between the stock market and hypothetical longevity bonds available during the period 1959-1999 was low. The team concluded that the bond should command a negligible risk premium over similar non-mortality related bonds. ${ }^{11}$

In this paper, we calculate how much it would cost the provider of a frozen plan to purchase insurance against aggregate mortality risk via longevity bonds. Using the findings from Friedberg-Webb, we conclude that, were the market to price aggregate mortality risk in accordance with the CAPM, then insurance would be available at negligible annual cost.

The remainder of the paper is organized as follows. In Section 2, we discuss the literature on trends in life expectancy and the Lee-Carter model. In Section 3, we explain how plan providers typically forecast mortality rates. We present a range of estimates of the impact of forecasting bias on pension obligations, and we calculate the impact of putatively unbiased estimates of aggregate mortality risk on pension plans and on the pension liabilities of S\&P 500 companies. In Section 4, we use the CAPM to calculate the cost to a provider of a frozen plan of hedging aggregate mortality risk using longevity bonds. Section 5 concludes.

\section{Modeling improvements in human longevity}

In this section, we introduce the Lee-Carter mortality model. We discuss its usefulness in making aggregate mortality forecasts over the long time horizons faced by pension providers and for quantifying the risks associated with those forecasts, and we discuss competing models.

There is considerable disagreement about the scope for improvements in human longevity over long time horizons (Siegel 2005). This disagreement sometimes pits "pessimistic" biologists, who argue that we may be approaching biological limits to

\footnotetext{
${ }^{10}$ Thus, even though the payments on a mortality-contingent bond are subject to an additional source of uncertainty, if that uncertainty generates a negative correlation between market returns and the mortalityrelated component of the return on the bond, then holders should accept a lower yield than that obtainable on equivalent bonds with fixed payments.

${ }^{11}$ The design of the bond could be engineered, though, by having payments made only to the extent that the number of survivors exceeds a base level, for example. This would make the payments more sensitive to mortality shocks and the beta correspondingly larger.
} 
longevity, versus "optimistic" mathematical demographers. To illustrate, Olshansky, Carnes, and Cassel (1990) argue from the biodemographer's perspective that life expectancy is unlikely to rise beyond 85 years. In contrast, Oeppen and Vaupel (2002) analyze "best practice" life expectancy, selecting the maximum life expectancy across countries in each period between 1840 and 2000. Since female life expectancy has increased at a fairly constant 2.5 years per decade, they conclude that we have not yet been affected by any biological limits to longevity, and that life expectancy at birth will attain 100 years in some country around the year 2060. Similarly, Tuljapurkar and Boe (1996) argue that neither theory nor evidence point to an irreducible component of mortality, while Sanderson and Scherbov (2004) point out that life expectancy in the leading country is already approaching 85 years, that the rate of increase in this "best practice” life expectancy is very nearly linear, and that there is little statistical evidence of a biological barrier to longevity. Some biologists disagree with the pessimistic view too, and Steven Austad, another famous researcher in the field, has wagered \$500 million with Jay Olshansky that someone recently born will live to 150 by 2150 .

The mathematical demography approach is extremely useful for making precise aggregate mortality forecasts. We employ the Lee-Carter (1992) model, which is, as we described earlier, the most widely-used model of population mortality improvements. The Lee-Carter model has been adopted by the U.S. Census Bureau, among others, and was viewed favorably by the Social Security Administration’s 1999 technical advisory panel. ${ }^{12}$ Lee-Carter found that their fitted model explains well over $90 \%$ of the withinage group variance in mortality rates. An attractive feature of the model is that it yields estimates of not only the expected rate of mortality decline, but also the probability distribution of outcomes.

In the Lee-Carter model, mortality risk $m$ at age $x$ in year $t$ is

$$
\ln [m(x, t)]=a_{x}+b_{x} k_{t}+e_{x, t}
$$

The parameters $a$ and $b$ vary with age. Lee-Carter estimate that a random walk with drift fits the time path of $k$, as follows:

$$
k_{t}=k_{t-1}-0.365+5.24 f l u+e_{t}
$$

\footnotetext{
${ }^{12}$ The Social Security Technical Panel on Assumptions and Methods (1999), p.64.
} 
where flu is the impact of the 1918 epidemic. We calculate that a one standard-deviation shock to $k$ translates into a roughly two-month change in age-65 life expectancy. This specification implies that there is no mean reversion in trends in mortality, so a shock to current mortality yields an equal percentage change in all subsequent periods' expected mortality. The linear $k$ trend translates into a constant percentage decline in mortality at any given age, and therefore a decreasing rate of increase in life expectancy. This is less extreme than either the optimistic view that life expectancy will continue to increase at about the rate experienced in the past, or the pessimistic view that life expectancy is inherently limited to around the age of 85 .

The Lee-Carter model predicts that mortality among people over 65 will decline at a rate of $1.13 \%$ a year. This is considerably higher than the intermediate forecast by the Social Security Administration (SSA) of $0.47 \%$ a year, increasing to $0.67 \%$ a year by 2029 , and it is even high relative to the high forecast of $0.70 \%$ a year rising to $1.17 \%$ a year by 2029. Both forecasts lie within the Lee-Carter model's 95\% confidence interval, though, in contrast to the low forecast of the SSA.

There are three reasons why forecasts made with the Lee-Carter model might transpire to be incorrect. The first is that realizations of the $e_{t}$ and $e_{x, t}$ error terms are zero in expectation but of course are likely to take other values. The $e_{x, t}$ term has little impact on the value of annuities because it affects only one period's mortality. In contrast, realizations of the $e_{t}$ term affect mortality not only this year, but also in all future years. The second possible source of error is the fact that, as with any statistical model, the parameters $a_{x}, b_{x}$, and $k$ are estimated and not known with certainty. Lee and Carter (1992) show in an appendix that these sources of error are relatively unimportant. The third source of error is simply that the model may be mis-specified, or that it fails to capture the probability of an event so rare that it does not appear in the historical data, or simply that the future turns out to be unlike the past.

The 95\% confidence interval of Lee-Carter forecasts for the next 50-60 years encompasses much of the disagreement among researchers as to whether, when and by how much, a deceleration in longevity gains will occur. It covers both the 2.5-years-perdecade linear increase in life expectancy at birth forecast by Oeppen and Vaupel (2002) and also a gradual deceleration in the rate of increase, as the point estimate in 2060 is 
1.65 years' increase in life expectancy at birth per decade. It predicts with $20 \%$ probability that population life expectancy at birth in 2060 will be more than the 100 years predicted by Oeppen and Vaupel. On the other hand, the model attaches perhaps too low a probability - less than $0.1 \%$ - to the other extreme view, that life expectancy at birth in 2060 will be as low as the 85 years predicted by Olshansky (1990). However, this "upside" risk is of much less concern to pension plan providers.

A variety of authors have followed up on Lee-Carter's work by proposing related specifications or further enhancements. ${ }^{13}$ These potential improvements in the model are not generally important for our application, as we discuss at length in Friedberg and Webb (2006). Nevertheless, we will mention a few points that may be relevant. We may believe that there is a small risk that medical breakthroughs will dramatically increase longevity, or conversely, that an epidemic of obesity and diabetes may reduce it. ${ }^{14}$ For example, Olshansky, Carnes, and Cassel (1990) calculate that eliminating cancer, all circulatory diseases, and diabetes would raise male and female life expectancy at age 50 by 15.30 and 15.02 years respectively, equivalent to a $75 \%$ reduction in mortality rates. This small risk increases with the time horizon and may be understated by the Lee-Carter model. Based on the Lee-Carter model, we calculate that such a reduction has even less than a $0.01 \%$ probability of occurring over a 30 -year period. Moreover, Japanese data show that mortality can decline dramatically even without such medical breakthroughs (Mak 1999), although Wilmoth (1998) suggests that the rate of decline in Japanese mortality is converging to that observed in other advanced countries. Because we have no means of quantifying the extent to which the Lee-Carter model understates the risk of dramatic mortality improvements, we restrict ourselves to sensitivity analyses later on. ${ }^{15}$

\section{Quantifying the aggregate mortality risk faced by defined benefit plans}

\footnotetext{
${ }^{13}$ For example, Cairns, Blake, and Dowd (2006) model mortality as a function of time and an age-time interaction term that follow a two dimensional random walk with drift.

${ }^{14}$ A repetition of the 1918 flu epidemic would have little impact because it would only affect one period's mortality.

${ }^{15}$ Some, like the United Kingdom Pensions Commission (2006), go further and argue that we are dealing with inherent uncertainty and have no real basis for making mathematically precise statements of confidence intervals.
} 
In this section, we describe how pension funds treat mortality risk in practice, and we evaluate these assumptions taking, alternately, the Lee-Carter model and Social Security Administration forecasts as unbiased benchmarks. We consider the effect of their apparent forecasting bias on plan providers' pension liabilities, and then the effect of aggregate mortality risk on unbiased estimates of these obligations. Finally, we consider whether mortality risk is large in relation to actual plan providers' profits and stock market capitalizations.

\subsection{Evaluation of plan providers' mortality assumptions}

Pension providers are required to report their accumulated and projected benefit obligations on Form 10-K. The 10-K statements about mortality assumptions are usually uninformative. For example, one large company reports that, "mortality rates are based on actual and projected plan experience.”16 Watson Wyatt collects annually the only survey data of companies' actuarial assumption, of which we are aware. ${ }^{17}$ Watson Wyatt (2006) reports that 53\% of plan providers in their survey use the GAM83 mortality table. Of those, only $1 \%$ use age setbacks for males and $6 \%$ do so for females, and only $9 \%$ of plans use mortality projections for both males and females. ${ }^{18}$

Our own discussions with members of the actuarial profession yield similar conclusions about typical actuarial assumptions. We are informed, further, that only in the very largest plans do mortality tables and projections incorporate the plan's actual mortality experience. We understand that in the minority of cases in which mortality is projected forward from GAM83 or RP2000, the projection is most often made only to a current date, with no continued improvements projected in the future. Whether they are projecting to the current date or beyond, the plan provider will typically use Projection Scale AA. Friedberg and Webb (2006) show, however, that the Lee-Carter model predicts faster mortality declines than Scale AA. Thus, even the small minority of plans

\footnotetext{
16 This appears in Form 10-K for General Motors on December 31, 2005, available on www.gm.com.

${ }^{17}$ A recent study at Cass Business School (2005) investigated the mortality assumptions used by corporations throughout the EU to value pension liabilities. It found that some companies in some countries projected mortality while those in others used period tables without projection.

${ }^{18}$ An age setback (setforward) involves calculating liabilities as if all participants were a specified number of years younger (older) than their actual age.
} 
that use Projection Scale AA to project future mortality reductions may overestimate mortality.

The GAM83 mortality table includes a 10\% reduction in mortality probabilities that provides some margin to absorb longevity increases. Our analysis of SSA period mortality tables indicates that male mortality among those over 60 had declined to $10 \%$ below 1983 levels by 1991, and to 21.4\% below by 2005. In contrast, female mortality in 2005 was only $1.9 \%$ below the 1983 level. We calculate that if a pension plan had average group annuitant mortality in 1983, equal numbers of men and women participants, and population level mortality declines from then onward, GAM83 approximates to current mortality.

Our discussions with actuaries indicate that in the past couple of years there has been a move towards using the RP2000 table. RP2000 is based on mortality experience from 1990 to 1994, projected to 2000, and lacks the 10\% cushion that GAM83 has. Watson Wyatt (2005) shows that although RP2000 predicts lower male mortality than GAM83, the reverse is true for women, reflecting the above differences between male and female mortality declines since 1983.

Pension plans and insurance companies are both in the annuity business. In contrast to pension plans, who as we have seen, often use outdated mortality tables, actuarial guidelines require insurance companies to develop "prudent best estimates” of mortality, while regulators require them to retain financial reserves against adverse mortality experience and investment returns. For a pension plan, the firm’s equity is a “financial reserve,” yet pension plans are, as we discuss later, exposed to greater aggregate mortality risk by reason of the longer duration of their liabilities.

Figure 1 shows how the various mortality tables and projections that we have discussed translate into life expectancy for individuals reaching age 60 between 2006 and 2056. To reduce the complexity of the graph, we show unisex mortality rates weighted by the projected proportions of males and females in the population at each age. The horizontal lines show unisex life expectancy as predicted by GAM83, RP2000, and the SSA's 1983 and 2000 period tables. The upward sloping lines are for the SSA's 2005 low, intermediate, and high mortality forecasts, and for the $2.5^{\text {th }}, 50^{\text {th }}$ and $97.5^{\text {th }}$ percentiles of the Lee-Carter model's forecasts from a jumping-off point of 2005 period 
mortality. When making our credible forecasts based on the Lee-Carter model, we need to select values of $a, b$, and $k$ that characterize mortality in 2005, the jumping-off year for our forecast. We adopt the approach of Lee and Miller (2001), who concluded that the most accurate forecasts are obtained by adjusting the values of $a$ so that the value of $k$ in the jumping-off year does not vary with age. ${ }^{19}$

Among the flat projections, the 1983 and 2000 period life tables from SSA show shorter life expectancy than the corresponding pension annuitant life tables, reflecting the fact that the group annuitants represented in the GAM83 and RP2000 forecasts have relatively low mortality. The difference between GAM83 and the SSA's 1983 period table (1.67 years) is greater than the difference between RP2000 and the SSA's 2000 period table ( 0.57 years) because of the $10 \%$ conservative margin built into GAM83, but not RP2000.

The upward sloping lines are all population projections and therefore not strictly comparable with the annuitant projections of GAM83 and RP2000. The SSA intermediate forecast predicts male and female life expectancy at age 60 in 2006 of 21.06 and 24.02 years, a weighted average of 22.60 years. The weighted-average low and high forecasts are 21.80 and 23.55 years, respectively.

The SSA high projection is close to the central forecast obtained from the LeeCarter model, reflecting the relative pessimism of the SSA's forecasts. The SSA's low projection lies increasingly below the $2.5^{\text {th }}$ percentile of the Lee-Carter projection. Notably, though, both the SSA's low forecast and the lower confidence interval of LeeCarter show continuing increases in life expectancy to levels considerably above both 1983 and 2000 period life expectancy. Thus, the life expectancies predicted by the SSA cohort tables and by Lee-Carter eventually far surpass GAM83 and RP2000, even though the latter predicted somewhat greater life expectancy than the 1983 and 2000 SSA life tables. A pension plan provider using GAM83 or RP2000 without any projection would underestimate longevity by increasing amounts, even if plan participants had population mortality rather than the somewhat lower mortality forecast by a comparison of RP2000 with the 2000 period mortality table. Another factor to consider is the socio-economic

\footnotetext{
${ }^{19}$ If we had simply chosen a single value of $k$ that best fitted the 2005 data, then the model would not fit observed mortality precisely at every age. The forecasts would include jumps in mortality in the following year that would average out to the trend decline in mortality.
} 
status of a plan's participants, which might lead to differences in not only current mortality but also the rate of mortality decline. Scahlick et al (2000) found evidence of widening socio-economic differences in mortality using older U.S. data from 1967 to 1986, but it is difficult to infer whether mortality differentials have continued to expand. $^{20}$

Lastly, Figure 1 indicates how the uncertainty surrounding mortality forecasts the basis of aggregate mortality risk - rises with forecasting horizons. Though not interpretable as a confidence interval, the difference between life expectancies obtained using the SSA's high and low mortality projections rises from 1.75 years in 2006 to 6.06 years by 2056. The 95\% confidence interval in the Lee-Carter model, which was quite narrow in 2006 at only 2.72 years, rises to 7.06 years by 2056 .

\subsection{The impact of forecasting bias on pension liabilities}

Our discussion above suggests that many pension providers are using outdated mortality forecasts. In this subsection, we consider the impact of this potential forecasting bias compared to the Lee-Carter and SSA forecasts, and in the next subsection we evaluate the magnitude of the aggregate mortality risk in those putatively unbiased forecasts. We will determine the impact of mortality risk on two measures of DB pension liabilities - the projected benefit obligation of continuing plans and the accumulated benefit obligation of frozen plans. The former takes account of projected salary increases of current workers until retirement, while the latter is based on current salary. Appendix A describes how these liability measures are calculated. ${ }^{21}$ We focus on the projected benefit obligation with respect to employees' service to date, which is straightforward to measure. Thus, we ignore the impact of mortality risk on the provision of benefits in relation to future service - so we underestimate the consequences for

\footnotetext{
${ }^{20}$ Table 7.1 in "The RP-2000 Mortality Tables" available from www.soa.org lists rates of mortality declines among various types of lives (Federal Civil Service, Social Security, Railroad Retirees, Group Annuity Lives, and Group Annuity Amounts) from roughly 1980 to the late 1990s, and we can discern no systematic differences among them that are related to their presumed average socio-economic status. However, as the RP-2000 report points out in Chapter 4, "the measurement of mortality improvement requires voluminous consistent data covering many years."

${ }^{21}$ Lazear (1986) argues that a main function of DB pension plan is to provide a bond for good employee behavior and facilitate an orderly exit of older workers from the firm, which is especially important when wages are sticky. For a review of the literature, see Gustman, Mitchell, and Steinmeier (1994).
} 
employers in the case that employees fail to bear mortality-related increases in the cost of providing future benefits through lower cash wages.

As previously discussed, there are a wide variety of mortality assumptions that plan providers could (and do) make. They could use GAM83 or RP2000 with no projection, projection to 2006, or full projection into the relevant future (and until very recently most have appeared to use GAM83 with no projection). We refer to these generically in our tables as “providers’ mortality assumptions.” There are also a variety of assumptions about projections of future mortality from other sources. One could assume that mortality will decline at the low, intermediate, or high rates predicted by the SSA, or at the $50^{\text {th }}$ percentile of the Lee-Carter model, and one could conduct a sensitivity analysis by assuming that mortality declined at the $2.5^{\text {th }}$ or $97.5^{\text {th }}$ percentile of the distribution of Lee-Carter mortality outcomes. ${ }^{22}$ We refer to these mortality forecasts in our tables as “credible mortality forecasts.” Each combination of assumptions results in different mortality predictions. As mentioned above, male mortality has recently declined by much more than female mortality. Unless this pattern is reversed in coming years, GAM83 provides a much less conservative forecast of male than of female mortality. We therefore present calculations for men and women separately.

Tables 1a and 1b show the percentages by which projected benefit obligations of current plans would be understated for representative employees at selected ages; results for accumulated benefit obligations of frozen plans are almost identical and are not reported. ${ }^{23}$ We use a $6.17 \%$ interest rate, the average used by surveyed pension plans to discount future pension obligations (Watson Wyatt 2004). We have to make additional assumptions in order to combine information from the providers' mortality assumptions (which are annuitant mortality tables from previous dates) with the credible forecasts (which project population mortality beginning at the current date). We assume that male

\footnotetext{
${ }^{22}$ Using the Lee Carter model, we run 5000 Monte-Carlo simulations of the evolution of aggregate mortality. For each simulation we calculate the present value of pension liabilities at cohorts aged 22 to 60 in 2005. Then, for each cohort, we calculate the $2.5^{\text {th }}$ percentile, the $50^{\text {th }}$ percentile, and the $97.5^{\text {th }}$ percentile of the present values.

${ }^{23}$ In practice, actuarial calculations incorporate a wide range of additional assumptions relating to withdrawals, terminations, disability, and early retirement. These assumptions will vary from plan to plan and are ignored for our purposes. Terminations reduce the present value of liabilities, particularly for younger workers, because benefits are forfeited if not vested or are not subject to future wage increases if vested.
} 
(female) annuitant mortality declined in the interim period at the same percentage rate at which male (female) population mortality declined. ${ }^{24}$

For males, the percentage understatements in Table 1a are dramatic at younger ages, reflecting the compounding of small mortality reductions over long periods of time. For example, the projected benefit obligation of a 22-year-old employee would be understated by $16.2 \%$ if the plan provider used GAM83, but instead mortality declined at the rate predicted by the SSA intermediate assumption. If mortality declined at the rate predicted by the Lee-Carter model, the understatement reaches $25.2 \%$. At age 60, the percentage understatements are much lower but still substantial - 6.4 and $11.2 \%$ respectively. The $10 \%$ margin in the GAM83 life table is insufficient to offset the failure to project mortality improvements. The percentage understatements for females (Table 1b) are smaller but still sizeable at younger ages. At age 22 the projected benefit obligation for a female employee would be understated by $6.1 \%$ under SSA intermediate assumption and 13.2\% under Lee-Carter mortality assumptions. At age 60, the percentage understatements are $1.1 \%$ and 5.4\%, respectively.

The dollar amounts of such obligations at younger ages are extremely small because employees have few years of service and because the eventual benefits are subject to substantial time-discounting. The age and tenure-weighted average understatement of liabilities depends on the average age, salary, and tenure of employees currently participating in DB plans, and also on the likelihood of the employee quitting before retirement. Table 2 reports relevant statistics obtained from the 2004 Survey of Consumer Finances, separately for males and females. The great majority of DB participants are middle-aged and older, and tenure grows substantially with age. Overall, as expected, men are more likely to have a DB plan, have longer tenure in the job, and higher annual earnings than women.

Table 3 reports, separately for male and female employees, the understatement of projected benefit obligations weighted by age, duration of service, and salary, assuming

\footnotetext{
${ }^{24}$ We do this by multiplying the mortality rates for the relevant credible forecast by the ratio of either GAM83 basic mortality to the mortality rate in the 1983 SSA period mortality table or the ratio of RP2000 mortality to the mortality rate in the 2000 SSA period mortality table, as appropriate.
} 
that all employees stay until retirement. ${ }^{25}$ We assume a $6.17 \%$ interest rate as before, a $2.5 \%$ inflation rate, and $1.1 \%$ real salary growth until retirement at age 60 . The average is heavily weighted in favor of older workers, not only because they predominate in DB plans but also because they have greater DB wealth given their longer tenure and are subject to shorter discounting to retirement.

The overall averages fall between the Table 1 values for ages 50 and 60 . For males, if the plan provider uses GAM83, the weighted projected benefit obligation is understated by $9.4 \%$ if mortality declines at the rate predicted by the SSA intermediate assumption and by $15.2 \%$ if it declines at the rate predicted by the Lee-Carter model. If the plan provider projects mortality to 2006, the understatement almost disappears under the SSA intermediate assumption, offset by the $10 \%$ conservative margin in GAM83. Even with projection to 2006, there remains a substantial $6.8 \%$ understatement if mortality declines follow the Lee-Carter model. If the plan provider uses the RP2000 table without projection, the understatements are somewhat lower than those obtained from GAM83 - 5.2\% if mortality follows the SSA intermediate forecast, and $10.8 \%$ if it follows the Lee-Carter model. But they are somewhat higher than GAM83 if the tables are projected to $2006-3.7 \%$ and $9.2 \%$ respectively under the above assumptions, reflecting the smaller impact of projection on the more recent RP2000 table.

For females, the understatements of weighted projected benefit obligations are much lower, due to the smaller decline in mortality from 1983 to date. For example, the understatement is $2.2 \%$ if the plan provider uses GAM83 and mortality declines at the SSA intermediate rate and $4.5 \%$ if it declines at the predicted Lee-Carter rate. The understatements are slightly lower if the provider projects mortality to 2006 or uses the RP2000 table.

\subsection{Agregate mortality risk in defined benefit pension plans}

In the last subsection, we evaluated the impact of biased forecasts of mortality improvements. Now, we consider the effect on a DB provider's pension liability of

\footnotetext{
${ }^{25}$ Turnover decreases dramatically with age. Although younger employees have a much higher probability of quitting before retirement, the dollar amount of their projected benefit obligation is relatively small, so our assumption has relatively little effect on the overall weightings.
} 
aggregate mortality risk - the risk that a putatively unbiased forecast of mortality turns out to be incorrect.

In the case of a continuing plan, we calculate the annual mortality risk faced by the plan provider. We assume that the plan provider correctly calculates his projected benefit obligation using the Lee-Carter model. We select values of $a$ and $k$ to match our 2005 estimate of annuitant mortality, which is obtained by multiplying the RP2000 mortality rates by the ratio of 2000 to 2005 mortality rates as shown in SSA period mortality tables. We construct gender-specific cohort mortality tables using the LeeCarter model. ${ }^{26}$ We run Monte Carlo simulations by drawing a realization of the $e_{t}$ term in equation (2) each year. The pension provider then revises the forecasts of $k$ for all future years accordingly and updates the calculation of projected benefit obligations. ${ }^{27}$

Table 4 reports our results. For 22-year-old male (female) employees, there is, in any year, a 5\% probability that the projected benefit obligation increases by $1.21 \%$ $(0.85 \%)$ or more. There is a $1 \%$ probability that it increases by $1.58 \%(1.11 \%)$ or more. For men, the risks peak at 1.24 and $1.62 \%$ at age 40 , declining to 0.88 and $1.15 \%$ by age 60. The age, tenure, and salary-weighted averages are 1.07 and $1.41 \%$, respectively. We view this risk as being moderate overall, while it is small in relation to (say) the risk of investing in equities.

In the case of a frozen plan, we calculate the present value of the risk to pension assets over the entire period during which the assets are spent down, and not just the annual risk that was reported for continuing plans in Table 4. We calculate the plan's accumulated benefit obligation, assuming that mortality follows the predictions of the Lee-Carter model and then run Monte Carlo simulations, noting the present value of the payments in each simulation. Table 5 reports our results. For 22-year-old male employees, there is a $5 \%$ probability that the projected benefit obligation exceeds the predicted amount by $6.4 \%$ or more. There is a $1 \%$ probability that it exceeds it by $7.6 \%$ or more. The percentage risk declines with age, since older employees have shorter remaining life expectancies, and there is less risk that realized mortality is much lower

\footnotetext{
${ }^{26}$ We estimated separate male and female results, holding $b$ and $k$ constant and allowing $a$ to vary by gender.

${ }_{27}^{2}$ In addition to using Lee-Carter to calculate the uncertainty regarding mortality improvements, we also use it to predict the trend in mortality declines. We obtain almost identical results when we adjust the value of $k$ to replicate the SSA intermediate forecast of mortality declines.
} 
than predicted. For 60-year-old employees, there is a 5\% probability that the projected benefit obligation exceeds the predicted amount by $2.3 \%$ or more. There is a $1 \%$ probability that it exceeds it by $2.9 \%$ or more. The results are quite sensitive to interest rates because at higher interest rates, payments in the distant future, which are forecasted with less certainty, are discounted much more heavily. To illustrate, at an interest rate of $3 \%$ as opposed to $6.17 \%$, the $5 \%$ and $1 \%$ probabilities at age 60 are 3.6 and $4.5 \%$ respectively. Weighing accumulated benefit obligations by the distribution of age, salary, and tenure of male employees, the $5 \%$ and $1 \%$ probabilities are 3.5 and $4.2 \%$ at a $6.17 \%$ interest rate and 5.1 and $6.2 \%$ at a $3 \%$ interest rate. The respective numbers are slightly lower for female employees.

Defined benefit pensions carry greater aggregate mortality risk than immediate voluntary annuities because a greater proportion of the payments lie in the more distant future, when there is greater uncertainty as to mortality rates. The above $5 \%$ and $1 \%$ ageweighted probabilities are a little higher than those computed from Friedberg and Webb (2006) for an immediate annuity sold to someone aged 65 when using a 3\% interest rate. They computed 5\% (1\%) values of 3.7 (5.3\%) for annuities sold to women and 4.2 (5.8\%) for annuities sold to men, with values for couples falling in between.

\subsection{The magnitude of the aggregate mortality risk faced by S\&P500 companies}

Most S\&P500 companies - 74.2\% of the total - offer DB pension plans and are therefore exposed to aggregate mortality risk through their pension plans. Credit Suisse First Boston (2006) compares the projected benefit obligations of S\&P500 companies with their market capitalizations. Projected benefit obligations total $\$ 1,488$ billion, or $12.6 \%$ of the $\$ 11,941$ billion S\&P500 market capitalization, so even substantial increases in projected benefit obligations would result in a total that was small in relation to that aggregate market capitalization.

A minority of companies has very substantial exposure, though. General Motors had a market capitalization of $\$ 11.033$ billion and a projected benefit obligation of \$105.175 billion, yielding the highest ratio of projected benefit obligations to market capitalization in the S\&P500. Even a small increase in GM’s projected benefit obligation due to an aggregate mortality shock would be large in relation to its market capitalization. 


\section{Using Longevity Bonds to Reallocate Aggregate Mortality Risk}

Longevity bonds could offer a mechanism for transferring aggregate mortality risk to the capital markets. The bonds can be structured so that payments are proportional to the number of survivors of a particular birth cohort. A plan provider investing in the bond would exchange the risk that his employees lived longer than expected for the likely much smaller risk that they lived longer than the reference group.

In this section, we show how the Capital Asset Pricing Model has been applied to aggregate mortality and stock return data to predict the magnitude of the mortality risk premium or discount that investors should demand on longevity bonds. We then calculate the potential cost to a pension fund of hedging aggregate mortality risk by purchasing such bonds. ${ }^{28}$

The bond's risk premium - the market price of aggregate mortality risk - can be priced using the Capital Asset Pricing Model (CAPM). The CAPM decomposes risk into its systematic and specific components. Idiosyncratic risk does not command a premium because it can be diversified away. Systematic risk, which is correlated with the market, cannot be similarly diversified away. The magnitude of the risk premium that an investor requires to hold a risky asset like a mortality bond is determined by its beta, defined as

$$
\beta_{b}=\frac{\operatorname{cov}\left(R_{b}, R_{e}\right)}{\sigma_{e}^{2}},
$$

the covariance of the bond with the market rate of return divided by the variance of the market return. The expected return on the mortality bond equals

$$
E\left(R_{b}\right)=R_{f}+\beta_{b}\left[E\left(R_{e}\right)-R_{f}\right],
$$

the risk-free rate plus beta multiplied by the excess of the expected market return over the risk-free rate.

Forward-looking investors will consider the impact of this year's mortality shock not only on this year's but also all future years' bond payments - in other words, on the expected present value of the income stream. The bond's beta therefore depends on two

\footnotetext{
${ }^{28}$ Although the opportunity to hedge via such bonds is more efficient, it should be kept in mind that heterogeneity in risk preferences among investors might itself create a de facto market for aggregate mortality risk, with investors who are particularly averse simply refraining from investing in companies that are heavily exposed.
} 
relationships: between the market portfolio and mortality shocks, and between mortality shocks and the present value of the income stream. The calculations take into account the likelihood that this latter relationship, and thus the bond's beta, will vary with the age of the reference population.

Since longevity bonds have yet to be issued, Friedberg and Webb (2006) calculate the returns that might have been earned had such a bond been available. They examine the past relationships between returns on the S\&P 500, U.S. mortality shocks, and the expected present value of the payments on such a bond using data from 1959 to $1999 .^{29}$ They calculate a beta for every age from 22 to 120, when the last member of the reference population is assumed to die. ${ }^{30}$

For example, the resulting beta was 0.005 for a bond with a reference population of age 65, with a 95\% confidence interval of [-0.005, 0.015]. The estimated beta is extremely small because of a slightly positive correlation between stock returns and mortality shocks that translates into a slightly positive correlation between stock returns and mortality bond returns. The point estimate of the latter correlation is 0.15 , with a confidence interval of [-0.15, 0.46], so we cannot rule out a zero correlation. But, even if the correlation were sizeable, the mortality bond return is a smooth series - in only three years between 1959-1999 would the mortality shock have changed the bond price by more than $1 \%$ - so the covariance between stock and mortality bond returns would still be small, and the beta on the mortality bond likewise small.

An investor in a longevity bond with a positive beta would require a very slightly higher return than that offered by a bond with a fixed coupon to compensate for the added risk. An important implication is that the market price of aggregate mortality risk is expected to be slightly negative, so an investor should obtain a higher expected return (though very slightly so) on a longevity bond than on an otherwise identical bond with a

\footnotetext{
${ }^{29}$ This assumes that investors use the Lee-Carter model to calculate the bond's expected present value. We recognize that the S\&P500 is simply a commonly used proxy for the undetermined "market portfolio" (Roll 1977).

${ }^{30}$ A complication is that expected future bond payments should be discounted not at the interest rate payable on a regular bond, but at that rate plus an aggregate mortality risk premium (or minus a discount). To do this, one would calculate the beta on a bond with a reference population of, say, age 119, compute the resulting aggregate mortality risk premium, add it to the expected $6.17 \%$ return to get a total expected return; then calculate the beta at age 118, using the risk-adjusted interest rate; and so on back to age 22. However, since the estimated risk premium is trivial, then the results would be almost identical.
} 
fixed coupon, though, again, the results do not rule out a price of zero. If the S\&P 500 commands a risk premium of 500 basis points, then at a beta of 0.005 , calculations based on the CAPM predict that mortality bonds should trade at a discount of only 2.5 basis points to otherwise similar non-mortality related bonds. This is for all practical purposes zero, suggesting that the markets might be willing to assume aggregate mortality risk at essentially zero cost.

\section{Conclusions}

Many households are insured against the risk of an uncertain lifespan through annuities that are provided by defined benefit pensions. The resulting mortality risk borne by companies that offer DB pension plans consists of idiosyncratic risk, since any particular pensioner may live longer than expected, and aggregate mortality risk, since pensioners may on average live longer than expected. We evaluate two components of aggregate mortality risk: the risk that $\mathrm{DB}$ plan providers may be using a biased estimate of participant mortality, and the risk that the mortality experience of a provider is lower than that predicted by an unbiased estimate.

Although there is obviously disagreement as to what might constitute an unbiased estimate, the two mortality tables, GAM83 and RP2000, commonly used by DB plan providers understate even current male longevity, and also substantially understate prospective male longevity, relative to forecasts made by both the Social Security Administration and the widely-used Lee-Carter model. Pension providers that based their calculations of plan liabilities on either mortality table without projecting mortality would substantially understate those liabilities. The potential understatement for men could be in the range of 6.7 to $15.2 \%$, given the range of forecasts implicit in the SSA and LeeCarter projections. In contrast, female longevity has not improved as much, so the potential understatement is much lower, ranging from 1.1 to $4.5 \%$, respectively.

Even if plan providers were to base their calculations on unbiased forecasts of mortality, they are still exposed to the risk that the forecast proves to be incorrect. We calculate that there is a $5 \%$ annual probability that the projected benefit obligation of a continuing plan would increase by $1.07 \%$ or more, and a $1 \%$ probability that it would increase by $1.41 \%$ or more. 
Longevity bonds are sometimes proposed as a means of transferring aggregate mortality risk to the capital markets. We show that if such bonds were to be priced in accordance with the Capital Asset Pricing Model, then aggregate mortality risk could be transferred at essentially zero cost. Yet, the opportunity to trade in aggregate mortality risk remains a "missing market." Although there have been a number of short-term bond issues, there has not to date been a single long-term bond of a type that might appeal to pension plans. The European Investment Bank attempted to launch such a bond, based on lives of those living in the United Kingdom, but the issue was withdrawn. Cairns, Blake, Dawson, and Dowd (2005) report that the bond was to be issued at a discount of 20 basis points compared to equivalent non-mortality related bonds, based on mortality forecasts of the U.K. Government Actuary's Department.

A few explanations might account for the failure of the EIB bond. First, our results show that, although aggregate mortality risk is sizeable, it is of a much smaller order of magnitude than, for example, asset return risk. Second, our calculations indicate that the market price of aggregate mortality risk might be close to zero. That might explain the market's reluctance to purchase a longevity bond yielding less than similar non-mortality related securities. Third, if pension plans really believe that they are going to experience the mortality rates predicted by GAM83, then the longevity insurance offered by EIB-type bonds appears very expensive in relation to the amounts at risk. Fourth, several people have suggested to us that the particular design of the EIB bond contributed to its unattractiveness. In particular, the issuers planned to transfer the aggregate mortality risk to the reinsurance market, which might explain the relatively high price compared to that which, our calculations suggest, would be available through the wider capital market.

A last possible explanation for the lack of demand for the EIB bond is that aggregate mortality risk may affect the value of the company less than the CAPM model would indicate. Treynor (1977) pointed out that the opportunity to liquidate one's pension fund can be thought of as providing the employer with a put option. This option increased in value when the Pension Benefit Guaranty Corporation was created in 1974, since the shareholders could put the pension obligations off to the government, and the option has been increasingly exercised in very recent years. The put option provides the 
employer with a mortality option that pays out if mortality does not decline too rapidly. Of course, the put option against the PBGC can only be exercised in certain circumstances, for example bankruptcy. Although the price of this option, as reflected in PBGC premiums, varies with the plan's funding status, the variation in price does not fully reflect the variation in risk. ${ }^{31}$ Moreover, the value of the option rises as aggregate mortality grows more uncertain. Purchasing insurance against aggregate mortality eliminates that part of the value of the put option that arises from aggregate mortality risk. To the extent that DB pension providers insure themselves through the PBGC, then our calculations about the impact of aggregate mortality risk on pension liabilities are pertinent for taxpayers rather than shareholders.

\footnotetext{
${ }^{31}$ The premium is $\$ 19$ per employee plus $\$ 9$ per $\$ 1,000$ of unfunded vested benefit, so it is partially related to risk.
} 


\section{References}

American Academy of Actuaries. 2004. "Fundamentals of Current Pension Funding and Accounting for Private Sector Pension Plans: An Analysis by the Pension Committee of the American Academy of Actuaries.” www.actuary.org .

Association of Consulting Actuaries. 2005. "Pensions: Challenges and Choices.” Response to the First Report of the Pensions Commission, 26 January.

Brown, Jeffrey and Peter Orszag. 2006. "The Political Economy of Government Issued Longevity Bonds.” Unpublished Working Paper, University of Illinois.

Cairns, Andrew, David Blake, Paul Dawson, and Kevin Dowd. 2005. "Pricing the Risk on Longevity Bonds.” Working Paper.

Cairns, Andrew, David Blake, and Kevin Dowd. 2006. "A Two Factor Model for Stochastic Mortality with Parameter Uncertainty.” Journal of Risk and Insurance forthcoming.

Deaton, Angus and Christina Paxson. 2004. "Mortality, Income, and Income Inequality Over Time in Britain and the United States.” National Bureau of Economic Research Working Paper No. 8534.

Dushi, Irena and Anthony Webb. 2004. "Household Annuitization Decisions: Simulations and Empirical Analyses.” Journal of Pension Economics and Finance 3(2).

Dushi, Irena and Anthony Webb. 2006. "Rethinking the Sources of Adverse Selection in the Annuity Market.” In Competitive Failures in Insurance Markets: Theory and Policy Implications, Chiappori, P., ed. MIT Press.

Friedberg, Leora, and Michael Owyang. 2005. "Explaining the Evolution of Pension Structure and Job Tenure.” Saint Louis Federal Reserve Bank Economics Working Papers No. 2002-022D.

Friedberg, Leora and Anthony Webb. 2006. "Life is Cheap: Using Mortality Bonds to Hedge Aggregate Mortality Risk.” National Bureau of Economic Research Working Paper No. 11984.

Gustman, Alan, Olivia Mitchell, and Thomas Steinmeier. 1994. "The Role of Pensions in the Labor Market: A Survey of the Literature.” Industrial and Labor Relations Review 47(3), 417-438.

Lazear, Edward P. 1986. "Retirement from the Labor Force.” In Handbook of Labor Economics, Vol. 1. Orley Ashenfelter and Richard Layard, eds. New York: Elsevier Science Publications, 305-55. 
Lee, Ronald and Lawrence R. Carter. 1992. "Modeling and Forecasting U.S. Mortality.” Journal of the American Statistical Association 87(419), 659-671.

Lee, Ronald and Timothy Miller. 2001. "Evaluating the Performance of the Lee-Carter Method for Forecasting Mortality.” Demography 38(4), 537-549.

Mak, A. 1999. “The Importance of Mortality Trends for Elderly Lives Products.” General and Cologne Life Re Australasia.

Milevsky, Moshe. 2006. "Killing the Law of Large Numbers: Is There a Mortality Risk Premium.” Unpublished Working Paper, University of Toronto.

Credit Suisse First Boston. 2006.

Oeppen, Jim and James Vaupel. 2002. “Broken Limits to Life Expectancy.” Science 296, 1029-1031.

Olshansky, Jay, Bruce Carnes, and Christine Cassel. 1990. "In Search of Methuselah: Estimating the Upper Bound to Human Longevity.” Science, New Series, 250(4981), 634-640.

Pensions Commission. 2006. "Implementing an Integrated Package of Pension Reforms: The Final Report of the Pensions Commission." http://www.pensionscommission.org.uk/publications/2006/finalreport/final_report.pdf

Pensions Institute. 2005. “Conference Summary.” First International Conference on Longevity Risk and Capital Market Solutions, February 18, 2005. http://www.pensionsinstitute.org/conferences/longevity/conference_summary_18.02.05.pdf

Roll, Richard. 1977. “A Critique of the Asset Pricing Theory’s Tests: Part 1: On Past and Potential Testability of the Theory.” Journal of Financial Economics 4, 129-176.

Sanderson, Warren, and Sergei Scherbov. 2004. "Putting Oeppen and Vaupel to Work: On the Road to New Stochastic Mortality Forecasts.” International Institute for Applied Systems Analysis Working Paper.

Schalick, Lisa Miller, Wilbur C. Hadden, Elsie Pamuk, Vicente Navarro, and Gregory Pappas. 2000. "The Widening Gap in Death Rates Among Income Groups in the United States from 1967 to 1986.” International Journal of Health Services 30(1), 13-26. 
Schieber, Sylvester. 2005. "The Evolution and Implications of Federal Pension Regulation.” In The Evolving Pension System: Trends, Effects, and Proposals for Reform, W. Gale, J. Shoven, and M. Warshawsky, eds. The Brookings Institution, 11-49.

Siegel, Jacob. 2005. "The Great Debate on the Outlook for Human Longevity: Exposition and Evaluation of Two Divergent Views" http://library.soa.org/library-pdf/mli05-1_XV.pdf

Social Security Advisory Board. 1999. "1999 Technical Panel on Assumptions and Methods” - Report. http://www.ssab.gov/1999TechnicalPanelRept.pdf

Treynor, Jack. 1977. “The Principles of Corporate Pension Finance.” Journal of Finance 32(2), 627-638.

Tuljapurkar, Shirpad, and Carl Boe. 1998. "Mortality Change and Forecasting: How Much and How Little Do We Know?” North American Actuarial Journal 2(4).

United Kingdom Pensions Commission. 2006. "A New Pension Settlement for the Twenty-First Century: The Second Report of the Pensions Commission.” Appendix E, 186.

Verrall, Richard, Terry Sithole, and Steven Haberman. 2005. "An International Comparative Study of Mortality Tables used in Pensions.” Cass Business School, City of London. http://www.cass.city.ac.uk/media/stories/resources/mortality.pdf

Watson Wyatt. 2004. "Accounting for Pensions and Other Postretirement Benefits (FAS) 2004.” Watson Wyatt Worldwide Research Report, www.watsonwyatt.com.

Watson Wyatt. 2005. "How Would the Proposed Changes to Mortality Standards Affect Plan Sponsors?”

http://www.watsonwyatt.com/us/pubs/insider/showarticle.asp?ArticleID=15435

Watson Wyatt. 2006. "2005 Survey of Actuarial Assumptions and Funding.” Watson Wyatt Worldwide Research Report, www.watsonwyatt.com.

Wilmoth, John. 1998. "Is the Pace of Japanese Mortality Decline Converging Towards International Trends.” Population and Development Review 24(3), 593-600. 
Figure 1. Life Expectancy at age 60 Under Various Mortality Assumptions

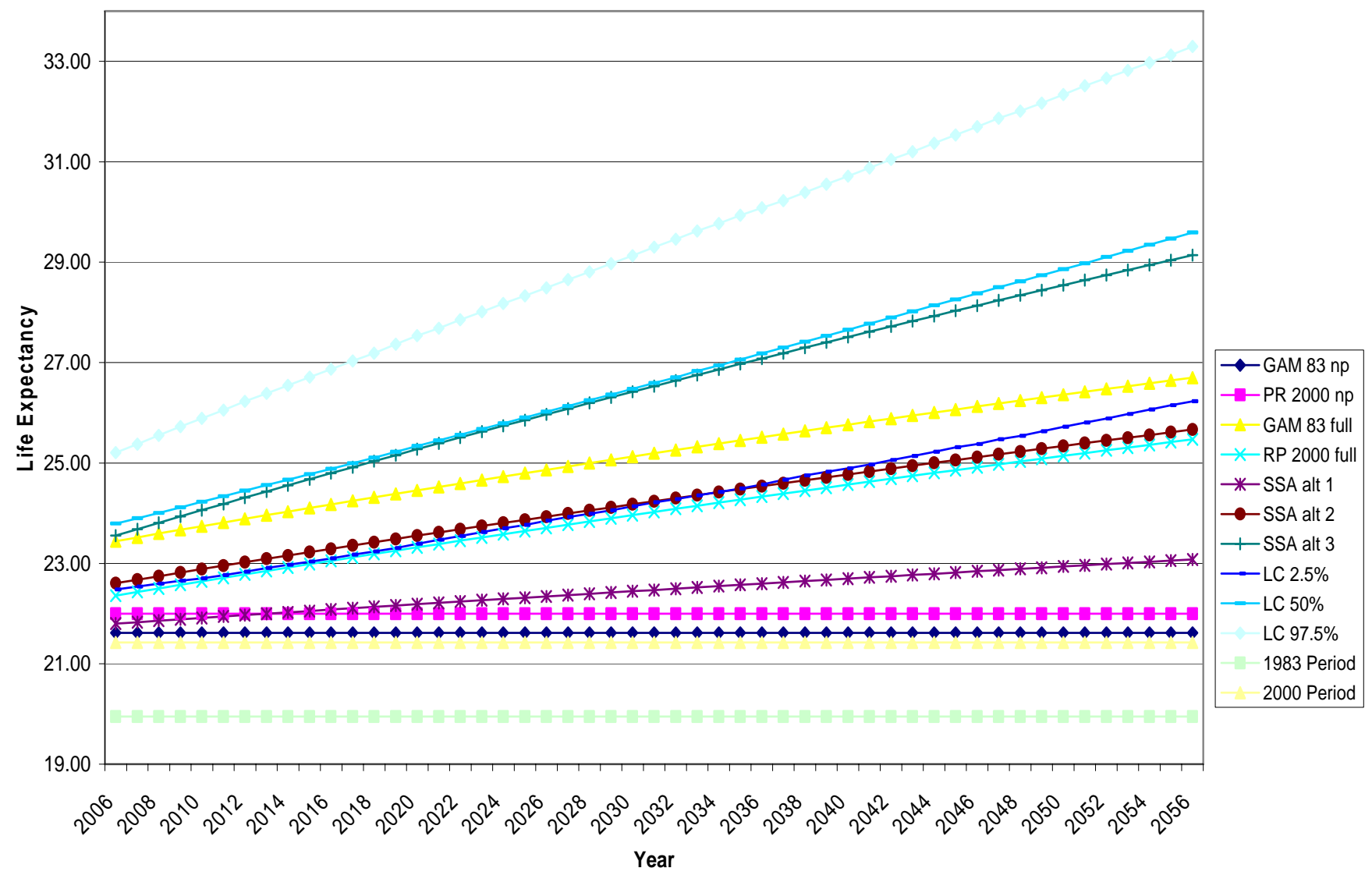

Notes: Each line indicates a projection using a different life tables and/or forecast.

GAM 83 and RP 2000 are period tables for voluntary annuitants, as described in the text. "np" indicates forecasts from the current date using these tables with no projection of mortality experiences to the current date, and "full" indicates that the data from these tables has been projected to the current date.

1983 Period and 2000 Period are SSA period tables.

SSA alt 1, 2, and 3 are the low, intermediate, and high projections for the population, taken from the 2005 Social Security Administration Trustees’ Report LC $2.5 \%, 50 \%$, and $97.5 \%$ are the lower bound of the 95\% confidence interval, the point estimate, and the upper bound of the 95\% confidence interval calculated from the Lee-Carter model, with 2005 as the jumping-off year, as described in the text. 
Table 1a: The Percentage Understatement of Projected Pension Obligations at Selected Ages Male

\begin{tabular}{|c|c|c|c|c|c|c|}
\hline \multirow{2}{*}{$\begin{array}{l}\text { "Providers' mortality } \\
\text { assumptions" }\end{array}$} & \multirow{2}{*}{ "Credible mortality forecast" } & \multicolumn{5}{|c|}{ Age } \\
\hline & & 22 & 30 & 40 & 50 & 60 \\
\hline \multirow[t]{6}{*}{ GAM 83} & 1983 Adjusted SSA Low & 0.103 & 0.095 & 0.084 & 0.073 & 0.048 \\
\hline & 1983 Adjusted SSA Intermediate & 0.162 & 0.145 & 0.124 & 0.102 & 0.064 \\
\hline & 1983 Adjusted SSA High & 0.233 & 0.207 & 0.173 & 0.136 & 0.083 \\
\hline & LC 2.5 percentile adjusted to 1983 & 0.189 & 0.172 & 0.148 & 0.126 & 0.090 \\
\hline & LC 50th percentile adjusted to 1983 & 0.252 & 0.226 & 0.194 & 0.161 & 0.112 \\
\hline & LC 97.5 percentile adjusted to 1983 & 0.307 & 0.279 & 0.240 & 0.196 & 0.135 \\
\hline \multirow[t]{6}{*}{ GAM83 projection to 2006} & 1983 Adjusted SSA Low & 0.010 & 0.003 & -0.006 & -0.010 & -0.014 \\
\hline & 1983 Adjusted SSA Intermediate & 0.063 & 0.049 & 0.031 & 0.016 & 0.002 \\
\hline & 1983 Adjusted SSA High & 0.128 & 0.105 & 0.075 & 0.048 & 0.020 \\
\hline & LC 2.5 percentile adjusted to 1983 & 0.089 & 0.073 & 0.053 & 0.038 & 0.026 \\
\hline & LC 50th percentile adjusted to 1983 & 0.146 & 0.123 & 0.095 & 0.071 & 0.047 \\
\hline & LC 97.5 percentile adjusted to 1983 & 0.197 & 0.171 & 0.137 & 0.103 & 0.069 \\
\hline \multirow[t]{6}{*}{ GAM83 Full projection } & 1983 Adjusted SSA Low & -0.101 & -0.092 & -0.078 & -0.058 & -0.039 \\
\hline & 1983 Adjusted SSA Intermediate & -0.054 & -0.050 & -0.044 & -0.033 & -0.024 \\
\hline & 1983 Adjusted SSA High & 0.004 & 0.001 & -0.003 & -0.003 & -0.006 \\
\hline & LC 2.5 percentile adjusted to 1983 & -0.031 & -0.028 & -0.024 & -0.012 & 0.000 \\
\hline & LC 50th percentile adjusted to 1983 & 0.020 & 0.017 & 0.015 & 0.019 & 0.021 \\
\hline & LC 97.5 percentile adjusted to 1983 & 0.065 & 0.060 & 0.054 & 0.049 & 0.042 \\
\hline \multirow[t]{6}{*}{ RP2000 } & 2000 Adjusted SSA Low & 0.054 & 0.047 & 0.038 & 0.029 & 0.018 \\
\hline & 2000 Adjusted SSA Intermediate & 0.108 & 0.094 & 0.076 & 0.056 & 0.034 \\
\hline & 2000 Adjusted SSA High & 0.172 & 0.150 & 0.120 & 0.088 & 0.052 \\
\hline & LC 2.5 percentile adjusted to 2000 & 0.134 & 0.119 & 0.098 & 0.080 & 0.059 \\
\hline & LC 50th percentile adjusted to 2000 & 0.190 & 0.169 & 0.141 & 0.113 & 0.081 \\
\hline & LC 97.5 percentile adjusted to 2000 & 0.241 & 0.216 & 0.183 & 0.146 & 0.104 \\
\hline \multirow[t]{6}{*}{ RP2000 projected to 2006} & 2000 Adjusted SSA Low & 0.037 & 0.030 & 0.021 & 0.013 & 0.005 \\
\hline & 2000 Adjusted SSA Intermediate & 0.089 & 0.076 & 0.058 & 0.040 & 0.021 \\
\hline & 2000 Adjusted SSA High & 0.153 & 0.131 & 0.102 & 0.072 & 0.039 \\
\hline & LC 2.5 percentile adjusted to 2000 & 0.115 & 0.101 & 0.080 & 0.063 & 0.046 \\
\hline & LC 50th percentile adjusted to 2000 & 0.171 & 0.149 & 0.122 & 0.096 & 0.068 \\
\hline & LC 97.5 percentile adjusted to 2000 & 0.220 & 0.196 & 0.163 & 0.129 & 0.090 \\
\hline \multirow[t]{6}{*}{ RP-2000 Full projection } & 2000 Adjusted SSA Low & -0.076 & -0.067 & -0.053 & -0.036 & -0.021 \\
\hline & 2000 Adjusted SSA Intermediate & -0.030 & -0.026 & -0.019 & -0.011 & -0.005 \\
\hline & 2000 Adjusted SSA High & 0.027 & 0.025 & 0.022 & 0.019 & 0.013 \\
\hline & LC 2.5 percentile adjusted to 2000 & -0.007 & -0.003 & 0.001 & 0.011 & 0.019 \\
\hline & LC 50th percentile adjusted to 2000 & 0.043 & 0.041 & 0.041 & 0.042 & 0.040 \\
\hline & LC 97.5 percentile adjusted to 2000 & 0.087 & 0.084 & 0.079 & 0.073 & 0.062 \\
\hline
\end{tabular}

Note: The SSA cohort tables, for each alternative, are either adjusted by the ration of GAM 1983 Basic mortality table to the 1983 SSA period table, or the ration of RP2000 mortality table to the 2000 SSA period table. Mortality tables generated using Lee-Carter (LC) model are adjusted in the same way, but instead of GAM 1983 Basic we use GAM 1983 table. The assumed interest rate is 6.17\%. 
Table 1b: The Percentage Understatement of Projected Pension Obligations at Selected Ages Female

\begin{tabular}{|c|c|c|c|c|c|c|}
\hline \multirow{2}{*}{$\begin{array}{l}\text { "Providers' mortality } \\
\text { assumptions" }\end{array}$} & \multirow{2}{*}{ "Credible mortality forecast" } & \multicolumn{5}{|c|}{ Age } \\
\hline & & 22 & 30 & 40 & 50 & 60 \\
\hline \multirow[t]{6}{*}{ GAM 83} & 1983 Adjusted SSA Low & 0.022 & 0.018 & 0.013 & 0.007 & -0.002 \\
\hline & 1983 Adjusted SSA Intermediate & 0.061 & 0.052 & 0.041 & 0.027 & 0.011 \\
\hline & 1983 Adjusted SSA High & 0.109 & 0.093 & 0.074 & 0.052 & 0.026 \\
\hline & LC 2.5 percentile adjusted to 1983 & 0.092 & 0.080 & 0.065 & 0.053 & 0.036 \\
\hline & LC 50th percentile adjusted to 1983 & 0.132 & 0.117 & 0.098 & 0.078 & 0.054 \\
\hline & LC 97.5 percentile adjusted to 1983 & 0.169 & 0.152 & 0.129 & 0.104 & 0.073 \\
\hline \multirow[t]{6}{*}{ GAM83 projection to 2006} & 1983 Adjusted SSA Low & -0.007 & -0.011 & -0.015 & -0.018 & -0.022 \\
\hline & 1983 Adjusted SSA Intermediate & 0.031 & 0.022 & 0.012 & 0.003 & -0.009 \\
\hline & 1983 Adjusted SSA High & 0.077 & 0.063 & 0.045 & 0.027 & 0.006 \\
\hline & LC 2.5 percentile adjusted to 1983 & 0.060 & 0.050 & 0.036 & 0.028 & 0.015 \\
\hline & LC 50th percentile adjusted to 1983 & 0.100 & 0.086 & 0.068 & 0.052 & 0.034 \\
\hline & LC 97.5 percentile adjusted to 1983 & 0.135 & 0.119 & 0.098 & 0.078 & 0.052 \\
\hline \multirow[t]{6}{*}{ GAM83 Full projection } & 1983 Adjusted SSA Low & -0.053 & -0.049 & -0.044 & -0.038 & -0.034 \\
\hline & 1983 Adjusted SSA Intermediate & -0.016 & -0.017 & -0.018 & -0.018 & -0.021 \\
\hline & 1983 Adjusted SSA High & 0.027 & 0.021 & 0.014 & 0.006 & -0.006 \\
\hline & LC 2.5 percentile adjusted to 1983 & 0.012 & 0.009 & 0.006 & 0.007 & 0.003 \\
\hline & LC 50th percentile adjusted to 1983 & 0.049 & 0.043 & 0.037 & 0.031 & 0.021 \\
\hline & LC 97.5 percentile adjusted to 1983 & 0.083 & 0.076 & 0.066 & 0.056 & 0.039 \\
\hline \multirow[t]{6}{*}{ RP2000 } & 2000 Adjusted SSA Low & -0.022 & -0.027 & -0.032 & -0.037 & -0.039 \\
\hline & 2000 Adjusted SSA Intermediate & 0.028 & 0.016 & 0.002 & -0.012 & -0.024 \\
\hline & 2000 Adjusted SSA High & 0.088 & 0.068 & 0.044 & 0.018 & -0.006 \\
\hline & LC 2.5 percentile adjusted to 2000 & 0.109 & 0.096 & 0.079 & 0.064 & 0.047 \\
\hline & LC 50th percentile adjusted to 2000 & 0.157 & 0.139 & 0.116 & 0.093 & 0.067 \\
\hline & LC 97.5 percentile adjusted to 2000 & 0.199 & 0.179 & 0.153 & 0.123 & 0.089 \\
\hline \multirow[t]{6}{*}{ RP2000 projected to 2006} & 2000 Adjusted SSA Low & -0.029 & -0.034 & -0.039 & -0.043 & -0.044 \\
\hline & 2000 Adjusted SSA Intermediate & 0.020 & 0.009 & -0.005 & -0.018 & -0.029 \\
\hline & 2000 Adjusted SSA High & 0.080 & 0.061 & 0.036 & 0.012 & -0.011 \\
\hline & LC 2.5 percentile adjusted to 2000 & 0.101 & 0.088 & 0.071 & 0.057 & 0.041 \\
\hline & LC 50th percentile adjusted to 2000 & 0.148 & 0.131 & 0.109 & 0.087 & 0.062 \\
\hline & LC 97.5 percentile adjusted to 2000 & 0.190 & 0.171 & 0.145 & 0.116 & 0.083 \\
\hline \multirow[t]{6}{*}{ RP-2000 Full projection } & 2000 Adjusted SSA Low & -0.083 & -0.080 & -0.073 & -0.066 & -0.057 \\
\hline & 2000 Adjusted SSA Intermediate & -0.037 & -0.039 & -0.040 & -0.041 & -0.042 \\
\hline & 2000 Adjusted SSA High & 0.019 & 0.011 & 0.000 & -0.012 & -0.025 \\
\hline & LC 2.5 percentile adjusted to 2000 & 0.039 & 0.037 & 0.033 & 0.032 & 0.027 \\
\hline & LC 50th percentile adjusted to 2000 & 0.084 & 0.078 & 0.069 & 0.061 & 0.047 \\
\hline & LC 97.5 percentile adjusted to 2000 & 0.123 & 0.115 & 0.104 & 0.089 & 0.068 \\
\hline
\end{tabular}

Note: The SSA cohort tables, for each alternative, are either adjusted by the ration of GAM 1983 Basic mortality table to the 1983 SSA period table, or the ration of RP2000 mortality table to the 2000 SSA period table. Mortality tables generated using Lee-Carter (LC) model are adjusted in the same way, but instead of GAM 1983 Basic we use GAM 1983 table. The assumed interest rate is $6.17 \%$. 
Table 2. Defined Benefit Participation, Tenure, and Salary by Age

\begin{tabular}{|c|c|c|c|}
\hline Age & Has DB plan (\% ) & $\begin{array}{l}\text { Mean Tenure } \\
\text { (years) }\end{array}$ & Mean Salary (\$) \\
\hline & \multicolumn{3}{|c|}{ Male } \\
\hline $22-24$ & 4.6 & 3.1 & 26905.51 \\
\hline $25-29$ & 10.8 & 3.0 & 40029.63 \\
\hline $30-34$ & 14.8 & 6.4 & 55993.36 \\
\hline $35-39$ & 11.3 & 8.7 & 70587.12 \\
\hline $40-44$ & 21.3 & 9.9 & 75743.89 \\
\hline $45-49$ & 20.1 & 16.4 & 67748.26 \\
\hline $50-54$ & 22.8 & 17.9 & 71100.26 \\
\hline $55-60$ & 18.1 & 22.1 & 83419.42 \\
\hline \multirow[t]{2}{*}{ Total } & 16.7 & 13.4 & 68687.37 \\
\hline & \multicolumn{3}{|c|}{ Female } \\
\hline $22-24$ & 4.5 & 3.9 & 18239.66 \\
\hline $25-29$ & 9.4 & 3.5 & 36620.92 \\
\hline $30-34$ & 9.5 & 5.7 & 42775.18 \\
\hline $35-39$ & 14.9 & 6.9 & 38667.70 \\
\hline $40-44$ & 11.0 & 10.5 & 38926.19 \\
\hline $45-49$ & 17.5 & 12.0 & 42276.39 \\
\hline $50-54$ & 16.7 & 16.5 & 41566.20 \\
\hline $55-60$ & 14.2 & 15.5 & 51228.55 \\
\hline Total & 13.0 & 11.0 & 41589.77 \\
\hline
\end{tabular}

Source: Survey of Consumer Finances 2004

Note: Percent with DB among all people age 22-60. Mean tenure and salary are conditional on having a DB plan. 
Table 3a: The Percentage Understatement of Projected Pension Obligations Weighted by Age, Tenure and Salary - Male

\begin{tabular}{|c|c|c|c|}
\hline \multirow[b]{2}{*}{ "Credible mortality forecast" } & \multicolumn{3}{|c|}{ "Providers' mortality assumptions" } \\
\hline & $\begin{array}{c}\text { GAM } 83 \text { no } \\
\text { projection }\end{array}$ & $\begin{array}{c}\text { GAM83 projection } \\
\text { to } 2006\end{array}$ & $\begin{array}{l}\text { GAM83 Full } \\
\text { projection }\end{array}$ \\
\hline 1983 Adjusted SSA Low & 0.067 & -0.010 & -0.055 \\
\hline 1983 Adjusted SSA Intermediate & 0.094 & 0.014 & -0.031 \\
\hline 1983 Adjusted SSA High & 0.125 & 0.043 & -0.004 \\
\hline LC 2.5 percentile adjusted to 1983 & 0.118 & 0.037 & -0.010 \\
\hline LC 50th percentile adjusted to 1983 & 0.152 & 0.068 & 0.020 \\
\hline \multirow[t]{2}{*}{ LC 97.5 percentile adjusted to 1983} & 0.184 & 0.098 & 0.048 \\
\hline & $\begin{array}{l}\text { RP2000 no } \\
\text { projection }\end{array}$ & $\begin{array}{c}\text { RP2000 projected } \\
\text { to } 2006\end{array}$ & $\begin{array}{l}\text { RP-2000 Full } \\
\text { projection }\end{array}$ \\
\hline 2000 Adjusted SSA Low & 0.027 & 0.012 & -0.034 \\
\hline 2000 Adjusted SSA Intermediate & 0.052 & 0.037 & -0.010 \\
\hline 2000 Adjusted SSA High & 0.082 & 0.066 & 0.018 \\
\hline LC 2.5 percentile adjusted to 2000 & 0.077 & 0.061 & 0.013 \\
\hline LC 50th percentile adjusted to 2000 & 0.108 & 0.092 & 0.042 \\
\hline LC 97.5 percentile adjusted to 2000 & 0.139 & 0.122 & 0.071 \\
\hline
\end{tabular}

Note: The assumed interest rate is $6.17 \%$, inflation rate $=2.5 \%$, and a real salary growth $=1.1 \%$.

Table 3b: The Percentage Understatement of Projected Pension Obligations Weighted by Age, Tenure and Salary - Female

\begin{tabular}{|c|c|c|c|}
\hline \multirow[b]{2}{*}{ "Credible mortality forecast" } & \multicolumn{3}{|c|}{ "Providers' mortality assumptions" } \\
\hline & $\begin{array}{l}\text { GAM } 83 \text { no } \\
\text { projection }\end{array}$ & $\begin{array}{c}\text { GAM83 projection } \\
\text { to } 2006\end{array}$ & $\begin{array}{l}\text { GAM83 Full } \\
\text { projection }\end{array}$ \\
\hline 1983 Adjusted SSA Low & 0.011 & 0.005 & -0.014 \\
\hline 1983 Adjusted SSA Intermediate & 0.022 & 0.016 & -0.004 \\
\hline 1983 Adjusted SSA High & 0.034 & 0.028 & 0.007 \\
\hline LC 2.5 percentile adjusted to 1983 & 0.032 & 0.026 & 0.005 \\
\hline LC 50th percentile adjusted to 1983 & 0.045 & 0.039 & 0.039 \\
\hline \multirow[t]{2}{*}{ LC 97.5 percentile adjusted to 1983} & 0.018 & 0.058 & 0.051 \\
\hline & $\begin{array}{l}\text { RP2000 no } \\
\text { projection }\end{array}$ & $\begin{array}{l}\text { RP2000 projected } \\
\text { to } 2006\end{array}$ & $\begin{array}{l}\text { RP-2000 Full } \\
\text { projection }\end{array}$ \\
\hline 2000 Adjusted SSA Low & 0.004 & 0.002 & -0.017 \\
\hline 2000 Adjusted SSA Intermediate & 0.014 & 0.011 & 0.002 \\
\hline 2000 Adjusted SSA High & 0.025 & 0.022 & 0.012 \\
\hline LC 2.5 percentile adjusted to 2000 & 0.026 & 0.023 & 0.013 \\
\hline LC 50th percentile adjusted to 2000 & 0.037 & 0.035 & 0.024 \\
\hline LC 97.5 percentile adjusted to 2000 & 0.049 & 0.046 & 0.036 \\
\hline
\end{tabular}

Note: The assumed interest rate is $6.17 \%$, inflation rate $=2.5 \%$, and a real salary growth $=1.1 \%$. 
Table 4. Annual Aggregate Mortality Risk as Percentage of Projected Benefit Obligations in Continuing Plans, by Gender

\begin{tabular}{|c|c|c|c|c|}
\hline \multirow[b]{2}{*}{ Participant Age } & \multicolumn{2}{|c|}{ Loss Probability of } & \multicolumn{2}{|c|}{ Loss Probability of } \\
\hline & $5 \%$ & $1 \%$ & $5 \%$ & $1 \%$ \\
\hline & \multicolumn{2}{|c|}{ Male } & \multicolumn{2}{|c|}{ Female } \\
\hline 22 & 1.209 & 1.583 & 0.849 & 1.112 \\
\hline 30 & 1.234 & 1.616 & 0.885 & 1.159 \\
\hline 40 & 1.237 & 1.620 & 0.900 & 1.179 \\
\hline 50 & 1.131 & 1.482 & 0.849 & 1.112 \\
\hline 60 & 0.882 & 1.156 & 0.705 & 0.925 \\
\hline $\begin{array}{l}\text { Weighted by Age, } \\
\text { Salary, and Tenure }\end{array}$ & 1.073 & 1.406 & 0.821 & 1.069 \\
\hline
\end{tabular}

Table 5. Lifetime Aggregate Mortality Risk as Percentage of Accumulated Benefit Obligations in Frozen Plans, by Gender

\begin{tabular}{|c|c|c|c|c|}
\hline \multirow[b]{3}{*}{ Participant Age } & \multicolumn{2}{|c|}{ Interest rate $=6.17 \%$} & \multicolumn{2}{|c|}{ Interest rate $=\mathbf{3} \%$} \\
\hline & \multicolumn{2}{|c|}{ Loss Probability of } & \multicolumn{2}{|c|}{ Loss Probability of } \\
\hline & $5 \%$ & $1 \%$ & $5 \%$ & $1 \%$ \\
\hline & \multicolumn{4}{|c|}{ Male } \\
\hline 22 & 0.064 & 0.076 & 0.090 & 0.109 \\
\hline 30 & 0.060 & 0.070 & 0.083 & 0.099 \\
\hline 40 & 0.052 & 0.064 & 0.072 & 0.092 \\
\hline 50 & 0.040 & 0.047 & 0.058 & 0.069 \\
\hline 60 & 0.023 & 0.029 & 0.036 & 0.045 \\
\hline \multirow[t]{2}{*}{$\begin{array}{l}\text { Weighted by Age, } \\
\text { Salary, and Tenure }\end{array}$} & 0.035 & 0.042 & 0.051 & 0.062 \\
\hline & \multicolumn{4}{|c|}{ Female } \\
\hline 22 & 0.048 & 0.057 & 0.070 & 0.085 \\
\hline 30 & 0.045 & 0.053 & 0.067 & 0.080 \\
\hline 40 & 0.040 & 0.050 & 0.060 & 0.075 \\
\hline 50 & 0.032 & 0.038 & 0.049 & 0.058 \\
\hline 60 & 0.020 & 0.025 & 0.033 & 0.040 \\
\hline $\begin{array}{l}\text { Weighted by Age, } \\
\text { Salary, and Tenure }\end{array}$ & 0.029 & 0.034 & 0.045 & 0.054 \\
\hline
\end{tabular}

Note: Results are based on Lee-Carter estimates. 


\section{Appendix: Calculating Pension Liability in Respect of Past Service}

Defined benefit pension plans typically relate pension benefits to final salary and years of service. Schieber (2005) reports that, until the early 1980s, pension plans funded their benefits on the basis of the entry age normal cost method. This involved choosing a level percentage of salary that would be sufficient to fund the benefits, provided the plan's actuarial assumptions were met. But, the benefits in respect of service at younger ages will be paid in the distant future and will therefore be subject to substantial time discounting. In consequence, at younger ages the assets in the plan will significantly exceed the sponsor's obligation if the plan were to be shut down.

In the early 1980s, the Federal Accounting Standards Board introduced rules requiring the use of the projected unit credit (PUC) method for pension accounting purposes. Under this method, the pension liability equals the present value of the proportion of future benefits that relates to past service. The calculation takes into account projected wage increases. The American Academy of Actuaries (2004) provides an example. Joe is aged 55, earns $\$ 50,000$ a year, has worked for 20 years, and is expected to retire at 65 on a salary of $\$ 75,000$ a year. His pension benefit is $1 \%$ of salary per year of service. His expected pension is $\$ 22,500$, of which $\$ 15,000$ relates to past service. Under the PUC method, the pension liability equals the present value at age 55 of a pension of $\$ 15,000$ a year starting at age 65 . This is referred to for pension accounting purposes as the projected benefit obligation.

Under the PUC method, the accounting cost of providing a year's pension obligation increases with age. From an economic perspective, this method understates the firm's obligation at younger ages.

Participants in a terminated plan will not benefit from future salary increases, and the analogous measure of the firm's liability is the accumulated benefit obligation, the present value of benefits earned in respect of past service, but excluding any salary increases. 


\section{RECENT WORKING PAPERS FROM THE \\ CENTER FOR RETIREMENT RESEARCH AT BOSTON COLLEGE}

Health Care Costs, Taxes, and the Retirement Decision: Conceptual Issues and Illustrative Simulations

Rudolph G. Penner and Richard W. Johnson, November 2006

Why Do Boomers Plan to Work So Long?

Gordon B.T. Mermin, Richard W. Johnson, and Dan Murphy, November 2006

Job Tenure and Pension Coverage

Alicia H. Munnell, Kelly Haverstick, and Geoffrey Sanzenbacher, October 2006

Has the Displacement of Older Workers Increased?

Alicia H. Munnell, Steven Sass, Mauricio Soto, and Natalia Zhivan, September 2006

No Place Like Home: Older Adults and their Housing

Timothy Smeeding, Barbara Boyle Torrey, Jonathan Fisher, David S. Johnson, and

Joseph Marchand, August 2006

Effects of Public Policies on the Disposition of Lump-Sum Distributions: Rational and Behavioral Influences

William G. Gale and Michael Dworsky, August 2006

Pensions, Social Security, Wealth and Lifetime Earnings: Evidence from the Health and Retirement Study

William G. Gale and John W.R. Phillips, August 2006

Determinants and Consequences of Bargaining Power in Households

Leora Friedberg and Anthony Webb, June 2006

Earnings and Women's Retirement Security

Alicia H. Munnell and Natalia Zhivan, June 2006

Mortality Heterogeneity and the Distributional Consequences of Mandatory Annuitization

Guan Gong and Anthony Webb, June 2006

All working papers are available on the Center for Retirement Research website

(http://www.bc.edu/crr) and can be requested by e-mail (crr@bc.edu) or phone (617-552-1762). 